\title{
Licenciaturas Interculturais: estudo de caso dos acadêmicos indígenas Fulni-ô
}

\author{
Licenciaturas interculturales: estudio de caso de los académicos indígenas \\ Fulni-ô
}

\author{
Intercultural Licenciaturas: case study of the Fulni-ô indigenous \\ academics
}

\author{
Gabriela Kássia Barbosa da Silva ${ }^{1}$ \\ Suzana Ferreira Paulino ${ }^{2}$
}

\begin{abstract}
Resumo
A universidade é um espaço que congrega diversos segmentos sociais e, em se tratando dos acadêmicos indígenas, cada um tem sua origem em determinado grupo étnico, com uma língua própria - característica que os identifica. Partindo do fato de que cada acadêmico indígena teve seu ensino básico dentro de sua comunidade, bem como um contato direto com sua língua materna no seu cotidiano, há que se reconhecer a existência de um choque linguístico-cultural quando o mesmo ingressa na universidade. Diante disso, a universidade deve se pautar em uma conduta de reconhecimento dessa trajetória educativa específica indígena, produzindo conhecimento de acordo com os valores e tradições desses povos, objetivando um processo de ensinoaprendizagem constante, coletivo e inclusivo. Nesse contexto, a presente pesquisa teve como objetivo geral discutir os desafios para o acesso e permanência de um povo indígena no ensino superior no atual contexto sociocultural brasileiro, a partir de dados relatados por acadêmicos indígenas Fulni-ô de Águas Belas/ PE.
\end{abstract}

Palavras-Chave: Ensino Superior; Fulni-ô; Licenciaturas Interculturais.

\section{Resumen}

La universidad es un espacio que congrega diversos segmentos sociales y, en lo que se refiere a los académicos indígenas, cada uno tiene su origen en determinado grupo étnico, con una lengua propia - característica que los identifica. A partir del hecho de que cada académico indígena tuvo su enseñanza básica dentro de su comunidad, así como un contacto directo con su lengua materna en su cotidiano, hay que reconocer la existencia de un choque lingüístico-cultural cuando el mismo ingresa en la universidad. En este sentido, la universidad debe guiarse en una conducta de reconocimiento de esa trayectoria educativa específica indígena, produciendo conocimiento de acuerdo con los valores y tradiciones de esos pueblos, objetivando un proceso de enseñanzaaprendizaje constante, colectivo e inclusivo. En este contexto, la presente investigación tuvo como objetivo general discutir los desafíos para el acceso y permanencia de un pueblo indígena en la enseñanza superior en el actual contexto sociocultural brasileño, a partir de datos relatados por académicos indígenas Fulni-ô de Aguas Belas / PE.

Palabras claves: Enseñanza superior; Fulni-o; Licenciaturas interculturales.

\footnotetext{
1 Especialista em Docência no Ensino Superior; Faculdade Senac Pernambuco (FACSENAC); Recife, Pernambuco, Brasil; gkbspos@gmail.com.

2 Doutora em Letras; Faculdade Integrada de Pernambuco (FACIPE); Recife, Pernambuco, Brasil; suzanafpenglish@yahoo.com.br.
} 


\begin{abstract}
The university is a space that congregates diverse social segments and, in the case of the indigenous academics, each one has its origin in a certain ethnic group, with a own language - characteristic that identifies them. Based on the fact that each indigenous academic had his basic education within his community, as well as a direct contact with his mother tongue in his / her daily life, it is necessary to recognize the existence of a linguisticcultural shock when he / she enters the university. Faced with this, the university should be guided by a process of recognition of this specific indigenous educational trajectory, producing knowledge according to the values and traditions of these peoples, aiming at a constant, collective and inclusive teaching-learning process. In this context, the present research had as general objective to discuss the challenges for the access and permanence of an indigenous people in higher education in the current Brazilian socio-cultural context, based on data reported by indigenous scholars Fulni-ô de Águas Belas / PE.
\end{abstract}

Keywords: Higher education; Fulni-ô; Intercultural degrees.

\title{
1. Introdução
}

Apesar de nos declararmos como uma sociedade multicultural - resultante do processo colonizador e seus diferentes grupos formadores, ainda persiste entre a maioria da população brasileira, nos seus mais diversos níveis sociais, e o que é mais preocupante, entre professores, uma visão genérica e equivocada sobre os povos indígenas como: indivíduos moradores da floresta, de culturas exóticas, com cabelos lisos, pinturas corporais, nus e abundantes adereços de penas. "Chamados de "tribos" na perspectiva etnocêntrica e evolucionista de uma suposta hierarquia de raças, onde os índios ocupariam o último degrau [...] imortalizados pela literatura romântica [...] são apresentados índios belos e ingênuos ou guerreiros e canibais" (SILVA, 2009, p. 2).

Essa falta de conhecimento é intensificada pela imagem que tradicionalmente é transmitida pelos livros didáticos e veiculada pela mídia, baseada em teorias simplistas e ultrapassadas, o "contato com os colonizadores e os vários processos de mudança cultural [...] eram simples relações de dominação impostas aos índios de tal forma que não lhes restava nenhuma margem de manobra, a não ser a submissão passiva a um processo de mudanças culturais" (ALMEIDA, 2010, p. 14).

Embora, nas últimas décadas, pesquisas interdisciplinares, que conjugam teorias e métodos históricos e antropológicos, venham aos poucos contribuindo para desconstruir equívocos e preconceitos sobre o papel desses povos e suas relações na formação da sociedade brasileira. Várias áreas do conhecimento como o Direito, a Sociologia, a História e a Educação vêm despertando para as "questões" indígenas, abrindo discussões críticas, construindo novas concepções que revisaram e revisam os planos teórico-metodológicos tradicionais acerca dessas sociedades (PACHECO, 2006 apud AMADO, 2010, p. 5). 
De acordo com essas novas interpretações, falar de índios no Brasil, hoje, significa falar de uma diversidade de povos, habitantes originários das terras conhecidas na atualidade como continente americano. E, segundo uma definição técnica das Nações Unidas (1986 apud LUCIANO, 2006, p. 27) povos e nações indígenas são aqueles que,

contando com uma continuidade histórica das sociedades anteriores à invasão e à colonização que foi desenvolvida em seus territórios, consideram a si mesmos distintos de outros setores da sociedade, e estão decididos a conservar, a desenvolver e a transmitir às gerações futuras seus territórios ancestrais e sua identidade étnica, como base de sua existência continuada como povos, em conformidade com seus próprios padrões culturais, as instituições sociais e os sistemas jurídicos.

Tais características refletem a necessidade de autoafirmação identitária desses povos perante uma sociedade impositora de uma única cultura nacional; assim como as mobilizações dos povos indígenas em torno das discussões e debates para a elaboração da Constituição em vigor, aprovada em 1988, possibilitando a garantia dos direitos indígenas (demarcação das terras, saúde e educação diferenciadas e específicas, etc.). De acordo com o capítulo VIII da referida Constituição, Art. 231: São reconhecidos aos índios sua organização social, costumes, línguas, crenças e tradições, e os direitos originários sobre as terras que tradicionalmente ocupam, competindo à União demarcá-las, proteger e fazer respeitar todos os seus bens (BRASIL, 1988).

Desde então, a sociedade em geral foi convocada a redescobrir esses povos como parte de uma formação múltipla da cultura nacional, reconhecendo e respeitando seus direitos específicos e diferenciados.

Diante do exposto, o presente artigo buscou responder à seguinte pergunta-problema: Quais os desafios enfrentados pelos povos indígenas para o acesso e permanência no ensino superior?

Para tanto, de acordo com a relevância do tema, a investigação teve como objetivo geral discutir os desafios para o acesso e permanência de um povo indígena no ensino superior no atual contexto sociocultural brasileiro e como objetivos específicos traçar o perfil do estudante indígena do ensino superior e verificar a adequação da Matriz Curricular à realidade sociocultural dos pesquisados, levando-se em conta toda trajetória vivenciada por esse povo dentro de sua comunidade específica, a partir de dados relatados por acadêmicos indígenas Fulni-ô de Águas Belas/ PE.

\section{Referencial Teórico}

\subsection{A Prática Pedagógica Indígena}


Para compreendermos como os povos indígenas entendem a educação escolar faz-se necessário diferenciarmos a educação escolar indígena da educação indígena. Pois, a educação indígena diz respeito:

aos processos próprios de transmissão e produção dos conhecimentos dos povos indígenas, enquanto a educação escolar indígena diz respeito aos processos de transmissão e produção de conhecimento não-indígena e indígena por meio da escola, que é uma instituição própria dos colonizadores (LUCIANO, 2006, p. 129).

O autor supracitado esclarece a importância da educação escolar indígena, apresentando suas contribuições ao afirmar que, a educação escolar indígena refere-se à escola apropriada pelos povos indígenas para reforçar seus projetos socioculturais e abrir caminhos para o acesso a outros conhecimentos universais, necessários e desejáveis, a fim de contribuírem com a capacidade de responder às novas demandas geradas a partir do contato com a sociedade global.

Até muito avançado do século XX, os povos indígenas acreditavam que a educação escolar era uma via exclusiva de aculturação e havia certa desconfiança e repulsa quanto à escolarização. Aqui, entende-se aculturação como: "mudanças culturais progressivas que conduziriam os índios a assimilação e consequentemente à perda de identidade étnica" (ALMEIDA, 2010, p. 14). Hoje em dia, os índios acreditam que a educação escolar, quando apropriada por eles e direcionada para atender às suas necessidades atuais, pode ser um instrumento de fortalecimento das culturas e das identidades indígenas.

$\mathrm{Na}$ educação indígena tradicional, os saberes ancestrais dos povos indígenas são transmitidos oralmente de geração em geração, sendo os pais e avós responsáveis por transmitirem aos seus filhos ou netos, desde a mais tenra idade, a sabedoria aprendida de seus ancestrais. Dessa forma, as crianças, desde cedo, vão aprendendo a assumir desafios e responsabilidades que lhes permitam inserir-se na vida social e o fazem, principalmente, por meio da observação, da experiência empírica e da autorreflexão proporcionada por mitos, histórias, festas, cerimônias e rituais realizados para tal fim. Por esta razão, não há necessidade da figura e do papel do professor, na medida em que este seria interpretado como o resultado da incapacidade dos pais, dos adultos e da própria comunidade de cumprirem o seu papel social (LUCIANO, 2006).

Nesse contexto, o Referencial Curricular Nacional para as Escolas Indígenas (RCNEI) - documento indutor e orientador de novas práticas, que contou com a participação de especialistas, técnicos e professores índios em sua formulação, apresenta desde 1998, considerações gerais sobre a educação escolar indígena, quer através da fundamentação 
histórica, jurídica, antropológica e pedagógica que sustenta a proposta de uma escola indígena que seja intercultural, bilíngue e diferenciada, quer através de sugestões de trabalho por áreas do conhecimento, que permitam a construção de um currículo específico e próximo da realidade vivida por cada comunidade indígena, na perspectiva da integração de seus etnoconhecimentos com conhecimentos universais selecionados (BRASIL, 1998).

No entanto, percebe-se que, na maioria dos casos, a educação escolar básica e superior continua ignorando as pedagogias indígenas, e quando isso acontece, a escola e as instituições de ensino estão contribuindo para o enfraquecimento ou o desaparecimento das culturas e dos próprios indígenas.

\subsection{O Ensino Superior e as Licenciaturas Interculturais}

De acordo com a Lei de Diretrizes e Bases da Educação, Lei no. 9.394 de dezembro de 1996, Cap. IV, Art. 43, a educação superior tem por finalidades:

I - estimular a criação cultural e o desenvolvimento do espírito científico e do pensamento reflexivo; II - formar diplomados nas diferentes áreas de conhecimento, aptos para a inserção em setores profissionais e para a participação no desenvolvimento da sociedade brasileira, e colaborar na sua formação contínua; III incentivar $o$ trabalho de pesquisa e investigação científica, visando o desenvolvimento da ciência e da tecnologia e da criação e difusão da cultura, e, desse modo, desenvolver o entendimento do homem e do meio em que vive; IV promover a divulgação de conhecimentos culturais, científicos e técnicos que constituem patrimônio da humanidade e comunicar o saber através do ensino, de publicações ou de outras formas de comunicação; V - suscitar o desejo permanente de aperfeiçoamento cultural e profissional e possibilitar a correspondente concretização, integrando os conhecimentos que vão sendo adquiridos numa estrutura intelectual sistematizadora do conhecimento de cada geração; VI estimular o conhecimento dos problemas do mundo presente, em particular os nacionais e regionais, prestar serviços especializados à comunidade e estabelecer com esta uma relação de reciprocidade; VII - promover a extensão, aberta à participação da população, visando à difusão das conquistas e benefícios resultantes da criação cultural e da pesquisa científica e tecnológica geradas na instituição (BRASIL, 1996).

Atendendo a esses objetivos, organiza-se a Educação Superior no Brasil que deve ser ministrada em instituições de ensino superior, públicas ou privadas, com variados graus de abrangência ou de especialização, a partir dos interesses de cada instituição de ensino superior (IES).

Diante dessa premissa, o ensino superior é percebido pelos envolvidos em movimentos indígenas como um lugar estratégico para obter conhecimentos fundamentais das diversas áreas de conhecimento que revertam para a defesa dos direitos, para a gestão dos territórios, fortalecimento das organizações, formulação de políticas públicas; enfim, para a 
concretização da autonomia dos povos indígenas (LUCIANO, 2006). Porém, ainda perdura a necessidade de valorização dos conhecimentos indígenas dentro das IES, rompendo com sua mera função de objeto da ciência ocidental.

As primeiras ações afirmativas de acesso diferenciado dos povos indígenas à universidade estão presentes na,

Lei no. 13.134, de 18 de abril de 2001, a qual determinava a disponibilização de 03 vagas suplementares nas universidades estaduais paranaenses, a serem disputadas entre os índios integrantes das sociedades indígenas daquele estado. Ainda em 2001, a Universidade do Estado do Mato Grosso - UNEMAT - se tornou a universidade brasileira pioneira na formação de professores indígenas em nível superior, por meio da implementação de seu curso de Licenciatura Intercultural: Projeto de Formação de Professores Indígenas - $3^{\circ}$ Grau Indígena (CAJUEIRO, 2001, p. 2).

Dessa forma, esses foram os primeiros projetos que tomaram como público-alvo os povos indígenas dos estados do Paraná e Mato Grosso.

Com relação às instituições pernambucanas, o estado conta, desde 2008, com o Programa de Formação para Professores Indígenas da Universidade Federal de Pernambuco Campus Caruaru/ PE, destinado a formar professores indígenas com o curso de Licenciatura Intercultural. Neste programa, são atendidos indígenas que já lecionam nas suas comunidades de origem, em turmas dos ensinos fundamental e médio. $\mathrm{O}$ curso oferece o mesmo rigor dos demais cursos de licenciatura da UFPE, mas é desenvolvido em módulos, com atividades presenciais, práticas de estudos cooperados e estágios supervisionados (UFPE, 2007).

As Licenciaturas Interculturais são cursos destinados a formar professores indígenas habilitando-os para a docência em escolas indígenas, nos anos finais do ensino fundamental e no ensino médio. Os cursos específicos para formação dos docentes indígenas devem integrar ensino, pesquisa e extensão, contemplando estudos de temas relevantes como línguas maternas, gestão e sustentabilidade das terras e das culturas dos povos indígenas. Esses cursos também devem promover a capacitação política dos professores indígenas como agentes interculturais na formulação e realização dos projetos de futuro das comunidades indígenas (BRASIL, 2007).

Porém, o Estado através do Programa de Apoio à Formação Superior e Licenciaturas Indígenas (Prolind) - de modalidade intercultural e bilíngue, dirige-se apenas à formação de professores indígenas (o que é uma exigência legal a partir da Lei de Diretrizes e Bases da Educação - LDB no. 9.394/96 e do Plano Nacional de Educação - PNE, 2001). Ou seja, o Estado até então não possui uma política voltada à criação de cursos específicos para indígenas em outras áreas de formação que não seja a formação pedagógica; assim como não possui uma política para a permanência dos cotistas. 
Diante desse quadro, nota-se que a estrutura universitária precisa ser modificada para que a educação superior deixe de ser um ambiente de distanciamento dos estudantes indígenas de suas comunidades e povos de origem, de reprodução da exclusão sociocultural e passe a ser um espaço de reafirmação das identidades e da construção permanente de autonomia e alteridades. Alteridade aqui foi usada no sentido de se colocar no lugar do outro, na relação interpessoal, com valorização e identificação, de dialogar com o outro (ALMEIDA, 2010). É de suma importância que os docentes universitários recebam uma formação orientada para o respeito e reconhecimento da diversidade cultural.

\subsection{Os Desafios do Ensino Superior Indígena}

A universidade é um espaço que congrega diversos segmentos sociais e, em se tratando dos acadêmicos indígenas, cada um tem sua origem em determinado grupo étnico, com uma língua própria - característica que os identifica. Partindo do fato de que cada acadêmico indígena teve seu ensino básico dentro de sua comunidade, bem como um contato direto com sua língua materna no seu cotidiano, há que se reconhecer a existência de um choque linguístico-cultural quando o mesmo ingressa na universidade (AMADO, 2010).

Ela, por sua vez, deve possibilitar o diálogo harmonioso com os diversos segmentos sociais participantes do processo educativo, especialmente os docentes universitários de acordo com as contribuições de Pimenta e Anastasiou (2002, p. 259) quando se referem aos atuais desafios para a docência universitária, "o avançar no processo de docência e do desenvolvimento profissional, mediante a preparação pedagógica não se dará em separado de processos de desenvolvimento pessoal e institucional: este é o desafio a ser hoje, considerado na construção da docência no ensino superior".

Essa constatação favorece a discussão da formação continuada em serviço que deve focalizar a pessoa do docente como sujeito que ocupa espaços determinantes à transformação da sociedade. Para tanto, faz-se necessário considerar que a especialidade da docência é proveniente do projeto institucional, como destaca Vasconcelos $(2008$, p. 4) "cuja habilitação deve vir articulada e legitimada pelo mesmo, concedendo-lhe, assim consistência para o cultivo da competência didático-universitária”.

Dessa forma, a universidade deve proporcionar momentos de reflexão cujo objetivo seja à mediação, a construção e reconstrução dos conhecimentos. Confirmando a tese de 
Demo (1998 apud VASCONCELOS 2008, p. 4) que "a universidade é, sobretudo, sinônimo de mutações, desafios, adversidades e confrontos com o mundo real".

Diante disso, os docentes universitários devem se pautar numa conduta de reconhecimento dessa trajetória educativa específica indígena, produzindo conhecimento de acordo com os valores e tradições desses povos, objetivando um processo de ensinoaprendizagem constante, coletivo e inclusivo.

\subsection{Os Fulni-ô}

Hoje, no Brasil, vivem mais de 800 mil índios, cerca de $0,4 \%$ da população brasileira, segundo dados do censo demográfico (IBGE, 2010). Eles estão distribuídos entre 683 terras indígenas e algumas áreas urbanas, dentre a população indígena urbana estão os índios da tribo Fulni-ô, que vivem no município de Águas Belas, Pernambuco, em uma aldeia de 11.500 hectares, localizada a 500 metros da sede da cidade com o mesmo nome do município. Sua população é de aproximadamente 4.336 índios, segundo dados da Fundação Nacional de Saúde (FUNASA, 2010).

A origem do nome Fulni-ô é muito antiga, significa "povo da beira do rio" e está relacionada com o rio fulni-ô que corre ao longo da aldeia de Águas Belas. Esse povo tem convívio constante com os não-índios, são bilíngues, vestem-se como os brancos, mas não perderam sua identidade, são extremamente conscientes dos seus direitos e da importância da preservação da sua cultura, mantém vivos os elementos do patrimônio cultural Fulni-ô. São os únicos indígenas do nordeste brasileiro que mantêm viva a língua nativa o Ia-tê ou (Yaathe) que significa "nossa boca, nossa fala, nossa língua" é oral, não possui cartilha. É aprendida pelos índios em casa com os familiares, no convívio doméstico ou por intermédio de uma escola bilíngue que a aldeia possui e que só lecionam índios Fulni-ô, não sendo aceitos nãoíndios ou índios de outra tribo, com vistas a preservar à língua e a cultura do povo Fulni-ô. Para eles, a origem do índio é a sua linguagem, por isso conseguiram mantê-la viva até hoje (GASPAR, 2003).

Além da aldeia a comunidade possui na reserva outro local de moradia, onde habitam durante três meses por ano por ocasião dos rituais do Ouricuri. Trata-se de um retiro religioso secreto, realizado anualmente nos meses de setembro, outubro e novembro, onde não é permitida a entrada de não-índios, pois é um espaço sagrado para eles. Durante esse período, os Fulni-ô mudam-se para a outra aldeia, também chamada Ouricuri, distante cerca de cinco quilômetros do local onde habitam. O que ocorre no Ouricuri não é revelado por eles. 
Os Fulni-ô vivem do artesanato da palha do ouricuri, da agropecuária de subsistência cultivo de plantações, criação de alguns bovinos e suínos, e ainda praticam a caça e a pesca. Suas manifestações culturais incluem a dança e a música, sendo o toré a mais tradicional. As músicas das danças são cantadas em português e em yaathe.

\section{Metodologia}

A presente pesquisa tratou-se de um estudo de caso de cunho qualitativo que utilizou como procedimentos metodológicos as pesquisas bibliográfica e de campo. $\mathrm{O}$ trabalho teve por objetivo discutir os desafios de acesso e permanência dos acadêmicos indígenas da tribo Fulni-ô, de Águas Belas/ PE, no ensino superior, com vistas a perceber as suas demandas.

Baseou-se nos pressupostos teóricos sugeridos por Amado (2010), Cajueiro (2011), Luciano (2006), Silva, (2009), Pimenta e Anastasiou (2002) entre outros. Buscaram-se dados que auxiliassem na compreensão da realidade enfrentada pelos acadêmicos Fulni-ô com vistas à fomentação da qualidade no processo de ensino-aprendizagem e a uma perspectiva de retorno desses indígenas, garantindo qualidade de vida para suas comunidades de origem.

A escolha da pesquisa qualitativa deve-se ao universo de abrangência: dos significados, das aspirações, das crenças, dos valores, das atitudes humanas e do compartilhamento de saberes adquiridos, pois, de acordo com Minayo (2010, p. 21), "o ser humano se distingue não só por agir, mas por pensar sobre o que faz e por interpretar suas ações dentro e a partir da realidade vivida e partilhada com seus semelhantes".

Quanto à pesquisa de campo, aplicou-se um modelo dissertativo de questionário a estudantes indígenas da tribo Fulni-ô de Águas Belas/ PE, analisando os dados coletados e destacando em suas falas informações relevantes para a constituição de um perfil desses estudantes indígenas, buscando compreender os desafios do acesso e permanência no curso de ensino superior no atual contexto sociocultural brasileiro.

Entende-se pesquisa de campo, na pesquisa qualitativa, como o recorte espacial que diz respeito à abrangência, em termos empíricos, do recorte teórico correspondente ao objeto da investigação (MINAYO, 2010) e seu uso justifica-se, pois, para a referida autora (2010, p. 61), "ela permite a aproximação do pesquisador da realidade sobre a qual formulou uma pergunta, estabelecendo uma relação com os "atores" que confirmam a realidade, construindo um conhecimento empírico importante para quem faz pesquisa social”.

Para tanto, foi utilizado como instrumento de coleta de dados um questionário de entrevista, contendo cinco questões que conseguiu registrar o perfil desses estudantes: quem 
são eles, faixa etária, dificuldades enfrentadas para cursarem o ensino superior, seus anseios e perspectivas em relação ao curso e à futura profissão.

A amostra foi composta por dez acadêmicos indígenas da tribo Fulni-ô de Águas Belas/ PE, dos quais quatro são do curso de Licenciatura Intercultural da Universidade Federal de Pernambuco - Campus Caruaru/ PE; outros quatro são do curso de Pedagogia da Universidade do Vale do Acaraú/ PE; e dois cursam os dois cursos: Licenciatura Intercultural e Pedagogia nas referidas instituições. Os pesquisados que nos forneceram dados para a pesquisa receberam, ao longo da mesma, a nomenclatura de A a $\mathrm{J}$.

Os dados obtidos a partir do questionário de entrevista foram classificados em seis categorias de acordo com os seguintes subtemas: Perfil dos Acadêmicos Indígenas Entrevistados; Dificuldades de Ingresso no Ensino Superior; Desafios para Permanência e Conclusão do Curso de Ensino Superior; Adequação da Matriz Curricular à Realidade Sociocultural; Sugestões para a Permanência dos Acadêmicos Indígenas no Ensino Superior; Pretensões de Retorno à Comunidade de Origem.

\section{Análise dos Dados e Resultados}

\subsection{Perfil dos Acadêmicos Indígenas Entrevistados}

O primeiro aspecto analisado foi o perfil da amostra. Foram solicitadas as seguintes informações: nome, idade, sexo, povo, curso e instituição de ensino superior. Analisando os dados dos entrevistados, observou-se que havia sete mulheres e três homens e percebeu-se que se tratava de um público relativamente jovem, em uma faixa etária entre 30 e 35 anos de idade. Muitos deles trabalham fora da aldeia e possuem família constituída, configurando um perfil de estudante distinto dos não-índios, que em sua maioria ingressam na universidade entre os 18 e 20 anos de idade, não trabalham e não possuem família constituída, tendo como preocupações os estudos e os dilemas da juventude.

Essa diferença etária entre os ingressantes no ensino superior índios e não-índios pode indicar maturidade desses estudantes indígenas, pois o ciclo de vida de um indígena possui fases definidas pelos ritos de passagem ou de iniciação, dentre eles a passagem da vida de criança à vida adulta, "ponto supremo da experiência da vida, necessária para a autorealização individual e coletiva da pessoa" (LUCIANO, 2006, p. 133). O rito é o momento em que o jovem demonstra que está preparado para assumir suas responsabilidades pessoais e 
como membro de uma coletividade e contribuir para o desenvolvimento e o bem-estar da comunidade e de seu povo.

4.2 A primeira pergunta do questionário de entrevista indagou se: Você enfrentou alguma dificuldade para ingressar no Ensino Superior? Quais? No que concerne a esse aspecto, todos os entrevistados consideram que enfrentaram algum tipo de dificuldade para ingressar no ensino superior, dentre elas destacam-se: a ausência de condições financeiras e o deslocamento da comunidade de origem até a instituição de ensino superior, evidenciando a problemática gerada pelo deslocamento para outras cidades em busca do ensino superior e a necessidade de ações de interiorização por parte do governo, das IES em cidades próximas às comunidades indígenas. Os Fulni-ô recorrem ao curso de ensino superior oferecido distante de sua comunidade de origem, deslocando-se de Águas Belas até Caruaru, cidade da instituição de ensino superior, percorrendo $183 \mathrm{~km}$ por trecho, cerca 2 horas.

Percebem-se tais dificuldades nas falas dos entrevistados A e E. Aquele afirmou:

[...] principalmente a dificuldade financeira de ter que abrir mão de coisas tão importantes para ter que financiar uma faculdade, outra grande dificuldade é ter que me deslocar da minha aldeia para ter que estudar fora e passar por tantas dificuldades inclusive de ter que me adaptar a outro contexto totalmente diferente do qual vivo na minha comunidade.

Por sua vez, E disse que,

a principal foi encontrar um ensino superior de acordo com a minha realidade, a outra foi com o calendário maleável a minha religião, conteúdos suficientes ao meu desempenho cultural, profissional e social. Outros são: o deslocamento, preconceitos e condições financeiras.

Em suma, quatro entrevistados apontaram dificuldades financeiras para manter-se no curso; três o deslocamento da sua cidade de origem até a cidade da instituição de ensino superior; dois dificuldades com o processo seletivo; e um, a falta de apoio familiar e os conteúdos ministrados. Esse último dado com relação aos conteúdos ministrados foi relatado por apenas um entrevistado do curso de Pedagogia, que não possui uma matriz curricular voltada para atender as necessidades do público indígena. Isso indica que os demais entrevistados consideram a matriz curricular do curso de Licenciatura Intercultural apropriada à realidade sociocultural do seu povo, quase não apresentando dificuldades com relação aos conteúdos ministrados.

Retomando as contribuições de Luciano (2006) sobre o significado atribuído pelos povos indígenas à educação escolar, entende-se que existe uma busca cada vez mais ampla pela escolarização em todos os níveis e modalidades de educação. Essa busca por melhores condições individuais e coletivas em várias terras e comunidades indígenas do Brasil tem 
promovido o êxodo para as cidades, o que gera problemas sociais de toda ordem, conforme pode ser observado nesta pesquisa, além de reforçar o esquecimento da língua materna e de outros aspectos da cultura indígena por parte dos jovens estudantes.

Revela-se, nesses dados, a necessidade de criação e ampliação, em regiões próximas às comunidades indígenas, de cursos específicos para índios, as chamadas Licenciaturas Interculturais que possuam uma matriz curricular voltada para a realidade sociocultural indígena, evitando descontentamentos e desistências por parte desses acadêmicos, devido à distância e ao afastamento das atividades da aldeia, bem como pela incompatibilidade dos conteúdos ministrados no decorrer do curso de ensino superior; assim como a criação de programas de apoio à permanência desses povos na universidade, uma vez que a dificuldade financeira e a distância foram os itens mais citados.

4.3 Na segunda, foi questionado: Em sua opinião, existe algum desafio com relação à permanência e conclusão do Ensino Superior? Quais? Quanto a esta questão, nove entrevistados relataram algum desafio. Destacam-se as falas de A e E. A afirmou que "existem vários desafios entre eles o preconceito que todo indígena sofre dentro do âmbito acadêmico que se torna muito difícil de ser enfrentado por conta do momento de sensibilidade o qual passamos longe de casa e da nossa família”.

A fala de E revelou-se carregada de reflexão e expressão da realidade enfrentada pelos Fulniô no Ensino Superior, o que provavelmente pode ser extendido a outros povos indígenas no mesmo contexto. O pesquisado indicou que,

a permanência desse curso em si é um desafio, para os povos indígenas e seus jovens [...]. A outra é a continuidade como a pós graduação, mestrado e doutorado intercultural, a garantia por enquanto é a proceguir um outros como: antropologia, sociologia, filosofia, letras e outros, e a conclusão do mesmos, os próximos é indefinido [sic].

O entrevistado E, ao relatar suas dificuldades com relação à permanência no curso de ensino superior, expressa uma visão holística, demonstrando interesse de continuar sua formação acadêmica em nível de pós-graduação, citando a ausência de continuidade da formação nos cursos de Licenciatura Intercultural e a necessidade de programas de pósgraduação específicos para índios.

Além dos entrevistados supracitados, quatro deles referem-se ao choque linguísticocultural; dois apontam o desacordo do calendário acadêmico com o período religioso indígena (o ritual do Ouricuri); e um, aponta a falta de apoio familiar e a ausência de formação continuada do curso de Licenciatura Intercultural. 
A última informação citada com relação à falta de continuidade do curso específico para indígenas em nível de pós-graduação apresenta-se como um fato preocupante, tendo em vista que a formação em outras áreas não-específicas para índios pode não atender às necessidades profissionais dos docentes indígenas, ressaltando a necessidade de criação de programas de pós-graduação específicos que contemplem as necessidades dos mesmos e que visem à aplicabilidade das pesquisas para a melhoria da qualidade de vida dessas comunidades.

Quanto ao desacordo do calendário acadêmico e o período religioso indígena, durante o período do ritual do Ouricuri todos os Fulni-ô que estudam ou trabalham fora de Águas Belas, pedem para se ausentar de suas atividades fora da comunidade e se concentram nele.

Diante desses dados, que revelam que $90 \%$ dos pesquisados encontram desafios para a permanência e conclusão do curso superior, nota-se a necessidade de compreender melhor as relações que se estabelecem dentro da universidade, em especial nos cursos específicos para indígenas. Amado (2010) adverte sobre a existência de um choque linguístico-cultural quando os indígenas ingressam na universidade, pelo fato de que cada povo teve seu ensino básico dentro de sua comunidade, bem como um contato direto com sua língua materna no seu cotidiano. É imprescindível que as instituições de ensino superior que atendem ao público índio façam adequações acadêmicas e curriculares que contemplem a realidade sociocultural e atendam às necessidades educacionais desses povos.

4.4 A pergunta seguinte foi sobre a adequação da Matriz Curricular dos dois cursos analisados, Licenciatura Intercultural da Universidade Federal de Pernambuco - Campus Caruaru/ PE e Pedagogia da Universidade do Vale do Acaraú/ PE, com a realidade sociocultural Fulni-ô. Foi-lhes solicitado que respondessem a pergunta: Você considera a Matriz Curricular do seu curso superior adequada à sua realidade sociocultural? De que forma ela influencia a sua permanência na universidade? Nove entrevistados consideraram a matriz curricular adequada à realidade sociocultural Fulni-ô, enquanto um não a considera adequada. Esse último faz parte do curso de Pedagogia, que não possui uma matriz curricular voltada para atender às especificidades dos povos indígenas. Isso pode indicar que o curso de Licenciatura Intercultural consegue cumprir a proposta de atender as necessidades educacionais específicas do público índio, formando professores para atuarem nas comunidades indígenas.

De acordo com o entrevistado A, que cursa Pedagogia e Licenciatura Intercultural, 
coisa haver com a minha realidade pois é um curso ofertado pela UFPE adaptado para a realidade cultural indígena [sic].

Isso demonstra a preocupação com a qualidade da sua formação acadêmica e a vontade de aprimoramento para a sua prática pedagógica.

O pesquisado $\mathrm{C}$ disse que "[...] A matriz curricular é muito relevante, e muito influente porque nos prepara para termos domínio de conteúdos, metodologia didática enfim complementa tudo aquilo que já sabemos só que de uma maneira mais científica" [sic].

Destaca-se nesta fala a necessidade de cientificidade dos conhecimentos, uma vez que se trata de um povo baseado nas tradições e crenças passadas de geração a geração. Observase, assim, um estabelecimento como sujeito do saber, instituído na cultura do outro, do nãoíndio.

Com $90 \%$ dos entrevistados considerando a Matriz Curricular adequada, os dados revelam que os cursos de Licenciatura Intercultural conseguem cumprir o que se propõem em relação à matriz curricular para formação de professores indígenas, conforme suas finalidades: integrar ensino, pesquisa e extensão, contemplando estudos de temas relevantes como línguas maternas, gestão e sustentabilidade das terras e das culturas dos povos indígenas (BRASIL, 2007). Apesar disso, eles ainda precisam de adequações nos seus calendários acadêmicos, como foi relatado por um entrevistado no subtópico anterior e a ausência de programas realizados pelo Estado de apoio financeiro e de fomento à pesquisa para os estudantes indígenas, ações que favorecem uma formação de qualidade que garantem o acesso e a permanência desses estudantes no ensino superior.

4.5 A pesquisa também solicitou dos estudantes sugestões de soluções para os problemas enfrentados com relação à não-permanência dos índios na universidade. Foram mencionados: apoio financeiro por parte do governo e de instituições responsáveis pela defesa dos direitos indígenas como a Fundação Nacional do Índio (FUNAI); incentivo familiar e de órgãos de fomento à educação, para os mesmos cursarem o ensino superior; ajuste do calendário acadêmico com o indígena, para evitar faltas nas aulas durante o ritual do Ouricuri; maior divulgação por parte dos órgãos responsáveis pelo fomento ao ensino e à pesquisa sobre a existência do curso de Licenciatura Intercultural específico para indígenas.

De acordo com os trechos da entrevista de A, há a necessidade de persistência e de adequação da academia com relação ao perfil desse novo público quando sugere que, "em primeiro lugar força de vontade por parte dos indígenas. E em segundo lugar seria muito bom se o mundo acadêmico se flexibilizasse mais um pouco e se adapta-se a realidade indígena e reconhecessem o diferente e o valorizasse" [sic]. 
Pela fala de $G$ pode-se compreender a força e as marcas identitárias dos Fulni-ô quando é colocado que,

como todos sabem nos indígenas somos sinônimos de luta e de resistência uma marca registrada de todos os povos. Então o caminho é sempre o mesmo nos articular com os movimentos sociais entre cada nação internamente e com os líderes, mostrando a todos os nossos direitos como índio e cidadão brasileiro [sic].

Percebe-se, nesse contexto, a importância dos agentes envolvidos no processo educativo para identificação das necessidades dos acadêmicos indígenas, assim como ressalta Amado (2010) em suas contribuições sobre o diálogo intercultural dentro da universidade. O professor deve se pautar em uma conduta de reconhecimento e respeito do processo de ensino e aprendizagem específico dos povos indígenas para a garantia de um ensino de qualidade que dialoga e acolhe as diferenças.

4.6 E, por fim, sabendo da importância do retorno desses indígenas, após a conclusão do curso, para a comunidade de origem, pensando na aplicação desses conhecimentos adquiridos para a melhoria da qualidade de vida da comunidade, a pesquisa buscou saber as pretensões desse regresso.

Os dez entrevistados afirmaram ter pretensões de retorno, após concluírem o curso, para trabalhar ou morar na aldeia do seu povo de origem. Ficou evidente a vontade de contribuir para com os seus pares com o conhecimento construído na academia, como pode ser percebido na fala de A quando afirma:

com certeza tudo que mais quero é continuar trabalhando na minha aldeia, porque é uma forma de contribuir com meu povo. Trazendo novos conhecimentos os quais poderão ser utilizados como defesa na hora de garantir uma educação específica, diferenciada e intercultural.

Outra fala marcante foi a de $\mathrm{G}$ ao ser enfático quando responde:

claro que sim, não penso jamais deixar de ensinar na minha aldeia. Porque eu preciso repassar os meus conhecimentos que adquiri com o curso utilizando todos os recursos metodológicos para poder proporcionar a nossos estudantes um ensino e aprendizagem mais qualificado e específico intercultural contemplando os eixos temáticos do povo [sic].

Aqui, percebeu-se a articulação dos saberes adquiridos com os prévios, mobilizandoos para o bem da sua comunidade de origem, valorizando suas práticas, especificidades e valores.

Nesse caso, os dados revelam-se extremamente animadores com relação ao retorno, corroborando o pensamento de Amado (2010, p. 3) sobre a importância da volta dos indígenas para suas comunidades, quando afirma que "dentro das universidades o que tem sido a 
preocupação é a "devolutiva" que eles darão para a sua comunidade de origem; assim como são grandes as expectativas em relação a esses acadêmicos por parte de sua comunidade".

Portanto, é de fundamental importância a elaboração de projetos que busquem desenvolver cursos superiores na área de educação indígena e promover melhorias nas diversas áreas de conhecimento para fortalecer a afirmação da identidade étnica, histórica e cultural, preservar a memória dos povos indígenas e garantir os seus direitos e territórios.

\section{Considerações Finais}

A proposta desta pesquisa foi discutir os desafios de acesso e permanência dos indígenas Fulni-ô no ensino superior e verificar a adequação da Matriz Curricular Intercultural às suas necessidades. Traçou-se um perfil do povo Fulni-ô extremamente politizado, crítico e consciente da importância da preservação da sua cultura, destacando-se por serem o único povo de Pernambuco que mantém viva a língua nativa, o Ia-tê ou (Yaathe).

Eles acreditam que através do ensino superior adquirem estratégias que podem ser revertidas para a defesa dos seus direitos, melhoria da qualidade de vida da sua comunidade e preservação da sua cultura através de um intercâmbio harmonioso entre as diferentes culturas. Verificou-se que a Matriz Curricular Intercultural atende às necessidades socioculturais do povo pesquisado, buscando formar professores indígenas conscientes politicamente e atuantes na formulação e realização de projetos nas diversas áreas de conhecimento que garantem a qualidade de vida de seu povo.

Ressaltaram-se alguns desafios a serem superados, objetivando a efetivação de uma cidadania cultural que se traduz em uma vida digna para esse povo, destacando-se: dificuldades financeiras e de deslocamento para a cidade da instituição de ensino, o choque linguístico-cultural na universidade, a ausência de formação continuada do curso de Licenciatura Intercultural e o desacordo do calendário acadêmico com o período religioso Fulni-ô (o ritual do Ouricuri).

Nota-se que as demandas apontam para a necessidade de ampliação das ações afirmativas nas Universidades Federais para que as instituições estabeleçam ações de interiorização, ou seja, que possam criar novos cursos ou faculdades no interior, para que os índios não tenham que se deslocar a cidades tão distantes das suas comunidades de origem. 
Também é imprescindível a criação de programas de manutenção para os estudantes a fim de promover a permanência deles; criação de programas de estágio remunerado e pesquisa para os estudantes indígenas, como forma de melhorar seu desempenho e adquirir experiência; criação de núcleos de apoio dentro das universidades que possam acompanhar de forma qualificada em termos pedagógicos, psicológicos e sociais aos alunos indígenas. Outra vertente das demandas aponta para a criação de cursos de graduação e programas de pósgraduação específicos para índios, de modalidade diferenciada e intercultural. Ou seja, cursos que lhes garantam uma formação superior, contudo, baseada na valorização da língua e cultura e no reconhecimento do valor dos conhecimentos indígenas.

O Estado, até agora, vem atendendo principalmente a última vertente mencionada. $\mathrm{Ou}$ seja, o financiamento através do Programa de Apoio à Formação Superior e Licenciaturas Indígenas (Prolind), mas que dirige-se apenas à formação de professores indígenas. Em Pernambuco, não existe uma política voltada à criação de cursos específicos para indígenas em outras áreas de formação que não seja a formação pedagógica, tampouco para a permanência dos cotistas e são incipientes as bolsas de nível estadual e Federal.

Conclui-se que o pleno acesso, a permanência e o êxito dos indígenas no ensino superior se traduzem na garantia dos direitos específicos e diferenciados dos povos indígenas, além de propiciar o intercâmbio entre diferentes saberes, experiências e conhecimentos. Confirmando a tese de que são importantes a criação e oferta de mais vagas nos cursos específicos para índios. Espera-se que esses dados iniciais apresentados nesta pesquisa contribuam para a reflexão e diferentes iniciativas de pesquisadores e envolvidos no processo de ensino aprendizagem superior, constituindo-se em uma importante oportunidade de debate com outros referenciais e paradigmas.

\section{Referências}

ALMEIDA, Maria Regina Celestino de. Os Índios na História do Brasil. Rio de Janeiro: FGV, 2010.

AMADO, Luiz Henrique Eloy. Educação Superior Indígena: desafios e perspectivas na construção de uma cidadania cultural. Uberlândia, MG, 2010.

BRASIL. Constituição da República Federativa do Brasil. Brasília, DF, Senado, 1988.

. Lei no. 9394 de dezembro de 1996. Lei de Diretrizes e Bases da Educação Nacional. Brasília, DF, 1996. 
Educação Escolar Indígena: diversidade sociocultural indígena ressiginificando a escola. Brasília: Secretária de Educação Continuada, Alfabetização e Diversidade, 2007. (Cadernos Secad 3).

. Conselho Nacional de Educação. Lei no. 10.172 de 09 de Janeiro de 2001. Plano Nacional de Educação. Brasília, DF, 2001.

1998.

Referencial Curricular Nacional para as Escolas Indígenas. Brasília: MEC/ SEF,

CAJUEIRO, Rodrigo. Os Povos Indígenas em Instituições de Ensino Superior Públicas Federais e Estaduais do Brasil: levantamento provisório de ações afirmativas e de licenciaturas interculturais. [S.1.]: Trilhas de Conhecimentos, 2001. Disponível em: <http://www.trilhasdeconhecimentos.etc.br>. Acesso em: 11 jul. 2011. Hora: 10:00:32. FUNDAÇÃO NACIONAL DE SAÚDE, FUNASA. Sistema de Informação da Atenção à Saúde Indígena (Siasi). Demografia dos Povos Indígenas. Brasília, 2010. Disponível em: <http://www.funasa.gov.br>. Acesso em: 16 dez. 2011. Hora: 08:11:14.

GASPAR, Lúcia. Índios Fulni-ô. Pesquisa Escolar On-Line, Fundação Joaquim Nabuco. Recife, 19 Ago. 2003. Disponível em: <http://basilio.fundaj.gov.br>. Acesso em: 05 out. 2011. Hora: 09:15:13.

INSTITUTO BRASILEIRO DE GEOGRAFIA E ESTATÍSTICA, IBGE. Censo Demográfico. Brasília, 2010.

LUCIANO, Gersem dos Santos. O Índio Brasileiro: o que você precisa saber sobre os povos indígenas no Brasil de hoje. Brasília: Ministério da Educação, Secretaria da Educação Continuada Alfabetização e Diversidade, LACED/ Museu Nacional, 2006.

MINAYO, Maria Cecília de Souza (Org.). Pesquisa Social: teoria, método e criatividade. Petrópolis, RJ: Vozes, 2010.

PIMENTA, Selma Garrido; ANASTASIOU, Léa das Graças. Docência no ensino superior. São Paulo: Cortez, 2002.

SILVA, Edson. Povos e Culturas Indígenas no Currículo Escolar. Recife: UFPE, Centro de Educação, 2009. (Versão da exposição apresentada no Fórum das Licenciaturas da UFPE).

UNIVERSIDADE FEDERAL DE PERNAMBUCO, UFPE. UFPE vai oferecer curso de Licenciatura Intercultural para professores indígenas. Recife, 25 Jul. 2007. Disponível em: <http://www.ufpe.br>. Acesso em: 10 dez. 2010. Hora: 11:16:19.

VASCONCELOS, Marilúcia Correia; AMORIM, Delza Cristina Guedes. A Docência no Ensino Superior: uma reflexão sobre a relação pedagógica. [S.1.]: FACAPE, 2008. Disponível em: <http://www.facape.br>. Acesso em: 15 dez. 2011. Hora: 10:45:37. 